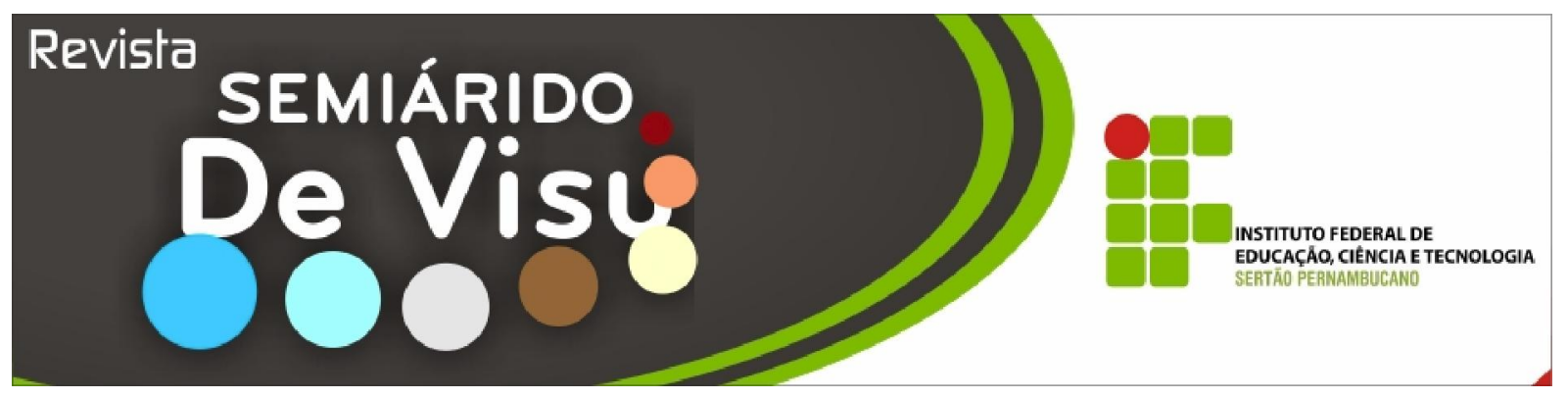

\title{
Influência de composto orgânico nas características físico-químicas de cenoura "Brasília" no município de Petrolina (PE)
}

\author{
Acácio Figueiredo Neto ${ }^{1}$, Silvana Belém de Oliveira ${ }^{2}$, Marcos dos Santos Lima ${ }^{1}$, Mariana da Rocha \\ Amorim $^{3}$, Raquel Mota Carneiro Figueiredo ${ }^{4}$ \\ Professores do Curso Superior em Tecnologia de Alimentos do IFET Sertão Pernambucano, Unidade Industrial - Rod. \\ BR 407, Km 08, Jardim São Paulo, (87) 3863-2330, acaciofneto@yahoo.com.br, marcoslima100@hotmail.com. \\ ${ }^{2}$ Graduada no Curso de Tecnologia de Alimentos do IFET Sertão Pernambucano e aluna do Curso de Biologia da UPE. \\ ${ }^{3}$ Aluna concluinte do Curso de Tecnologia de Alimentos do IFET Sertão Pernambucano. \\ ${ }^{4}$ Gestora dos Laboratórios da Embrapa Semiárido, Petrolina - PE, raquel.figueiredo@cpatsa.embrapa.br
}

RESUMO: O trabalho foi desenvolvido com o objetivo de avaliar o efeito do composto orgânico no cultivo de cenouras da cultivar "Brasília" e sua influência na fase pós-colheita dessa hortaliça. O experimento foi conduzido em uma horta comunitária em sistema de cultivo tradicional (irrigado), localizada no município de Petrolina - PE. O composto orgânico foi constituído de esterco caprino curtido (40\%) e restos vegetais $(60 \%)$. As raízes foram colhidas 92 dias após a semeadura, onde logo em seguida foram levadas para o laboratório de pós-colheita para as análises. Os dois tratamentos para o cultivo da cenoura foram avaliados a partir da colheita para verificar qual a influência do composto orgânico no produto colhido através das análises de umidade, sólidos solúveis (SST), acidez total titulável (ATT), relação SST/ATT, carotenóides totais e firmeza da polpa. A análise estatística demonstrou que houve diferença significativa entre as principais características físico-químicas da cenoura ao nível de $5 \%$ entre os tratamentos nas diversas análises realizadas, indicando que a utilização do composto orgânico no cultivo da cenoura é uma ferramenta promissora na manutenção de sua qualidade e teor nutricional para fase de pós-colheita.

Palavras-chave: hortaliça, pós-colheita; qualidade nutricional.

\section{Influence of organic composition in the physicochemical characteristics of the "Brasília" carrot in the city of Petrolina (PE)}

\begin{abstract}
This study was developed with the objective of evaluating the effect of the organic composition in the cultivation of "Brasília" carrots and its influence in the postharvest phase of this vegetable. Experiments were driven in a community vegetable garden in traditional cultivation system (irrigated), located in the city of Petrolina - PE. The formulation of the organic compound was made with $40 \%$ of tanned goat manure and $60 \%$ of residues of vegetable remains. The rootses were picked 92 days after sowing, later, they were taken to the postharvest laboratory for analyses. The two treatments for the cultivation of the carrot were assessed, starting from the harvesting phase, in order to examine the influence of the organic compound in the product, through the analyses of humidity, total soluble solids (TSS), total tritable acidity (TTA), TSS/TTA relation, carotenoids and pulp firmness. The statistical analysis demonstrated that there was a significant difference among the main physicochemical characteristics of the carrot at the level of 5\% among the several analysis, indicating that the use of the organic compound in the cultivation of the carrot is a promising tool in the maintenance of its quality and nutritional value for the postharvest phase.
\end{abstract}

Key words: vegetable, postharvest, nutritional quality 
Acácio Figueiredo Neto et al.

\section{Introdução}

$$
\Lambda_{\begin{array}{l}
\text { adubação química em cenoura é } \\
\text { uma prática agrícola que traz } \\
\text { resultados }
\end{array} \text { satisfatórios em }}
$$

termos de produtividade. Contudo, deve-se levar em consideração a qualidade final do produto, pois o uso desordenado de fertilizantes químicos pode prejudicar à saúde dos consumidores, onerar os custos de produção e contribuir para a poluição do solo e mananciais de água.

Atualmente, tem-se empregado adubos orgânicos de várias origens no cultivo de hortaliças, destacando-se o composto orgânico, que além de proporcionar melhoria das propriedades físicas, químicas e biológicas do solo, reduz o uso de adubos minerais (Souza et al., 2005) e dependendo do grau de decomposição dos resíduos, pode ter efeito imediato no solo (Vidigal et al., 1995).

A cenoura (Daucus carota L.) é originária do Sudoeste Asiático, região semiárida do Afeganistão é uma hortaliça da família Apiaceae, do grupo das raízes tuberosas, cultivada em larga escala nas regiões Sudeste, Nordeste e Sul do Brasil (Filgueira, 2003). Essa raiz responde à adubação orgânica, especialmente em solos de baixa fertilidade ou compactados. Porém, é fundamental que o adubo orgânico esteja bem curtido, pois é lançado sobre os canteiros, e logo é incorporado antes do plantio (Embrapa Hortaliças, 2007). A forma de minimizar os efeitos negativos destes solos com baixa fertilidade seria o uso de resíduos orgânicos decompostos ou semi descompostos (Vieira, 1996).

Segundo Salgado et al. (1998), as hortaliças, em sua maioria, necessitam de grandes quantidades de nutrientes, devido a seus ciclos curtos. Sabe-se, que o uso de matéria orgânica influencia positivamente na germinação e enraizamento de oleráceas, além de estimular o crescimento e a absorção de nutrientes pela planta (Negrini \& Melo, 2007).

Os efeitos benéficos dos resíduos orgânicos na cultura da cenoura, relacionam-se com o elevado teor de matéria orgânica do solo, permitindo maior penetração e distribuição radicular, altos índices de agregação, de aeração e da capacidade de infiltração e armazenamento de água (Nogueira, 1984; Araújo et al., 2004).

A escolha do resíduo orgânico se deu em função da disponibilidade, variando entre regiões e conforme a cultura em que será utilizado (Kiehl, 1985). Na região de Petrolina - PE a caprinovinocultura produz uma grande quantidade de esterco, o que possibilita sua utilização para a melhoria dos solos cultivados com hortaliças. Resultados experimentais demonstraram que, para a cultura da cenoura, a incorporação de $7 \mathrm{t} \mathrm{ha}^{-1}$ de cama de frango proporcionou maior massa de folhas (45-73 dias após a semeadura) e maior massa de raízes (115 dias após a semeadura) (Vieira, 1996).

De acordo com Muller (1982), o fornecimento de nutrientes minerais, principalmente aqueles onde o solo não dispõe em condições satisfatórias durante o ciclo vegetativo, o acúmulo desses nutrientes pela planta pode influenciar a qualidade das raízes no armazenamento. Portanto, quando houver necessidade de optar pela vida pós-colheita no aspecto de armazenamento, é conveniente escolher cenouras cultivadas em solos mais equilibrados nutricionalmente, colhidas no estádio adequado de maturação, inteiras, firmes, sem ataque de insetos e de microrganismos e livres de impurezas (Chitarra \& Chitarra, 2005).

Os carotenóides existentes na cenoura, responsáveis pela cor alaranjada das raízes, têm atividade pró-vitamina $\mathrm{A}$, ou seja, quando ingeridos pelo ser humano são transformados em vitamina A, constituindo em uma das principais fontes desta vitamina para a população (Spagnol et al. 2006), porém são necessárias técnicas que viabilizem sua produção sem a utilização de agroquímicos, tendo em vista a qualidade do produto. Como expõe Chitarra \& Chitarra (2005), as propriedades que tornam frutas e hortaliças apreciadas como alimento, dizem respeito à aparência, sabor, odor, textura e o valor nutritivo.

Considerando a importância do estudo teórico e prático dos parâmetros de qualidade da cenoura "Brasília" cultivada na região de Petrolina, o presente trabalho teve o objetivo de 
Acácio Figueiredo Neto et al.

avaliar o efeito da aplicação de composto orgânico e sua influência sobre as características físico-químicas na fase de póscolheita dessa hortaliça.

\section{Material e métodos}

Tabela 1. Análise textural e característica química do solo, Petrolina - PE, 2008.
Caracterização do solo

$O$ solo foi analisado física $e$ quimicamente para fins de caracterização (Tabela 1).

\begin{tabular}{|c|c|c|c|c|c|c|c|c|c|c|c|c|c|}
\hline \multicolumn{3}{|c|}{ Granulometria } & $\mathrm{pH}$ & $\mathrm{Ca}^{2+}$ & $\mathrm{Mg}^{2+}$ & $\mathrm{K}^{+}$ & $\mathrm{Na}$ & $\mathrm{Al}^{3+}$ & $\mathrm{H}+\mathrm{Al}$ & SB & $\mathrm{T}$ & \multirow[t]{2}{*}{$\mathrm{MO}$} & \multirow[t]{2}{*}{$\mathrm{P}$} \\
\hline A. Total & Silte & Argila & & & & & & & & & & & \\
\hline \multicolumn{3}{|r|}{ 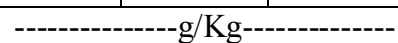 } & - & 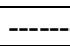 & 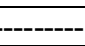 & $-\mathrm{cm}$ & $\mathrm{ddm}^{3}$ & & & & & $\mathrm{~g} / \mathrm{kg}$ & $\mathrm{mg} / \mathrm{dm}^{3}$ \\
\hline 899,96 & 92,36 & 7,68 & 6,7 & 1,1 & 0,4 & 0,10 & 0,02 & 0,05 & 0,66 & 1,62 & 2,28 & 4,84 & 15 \\
\hline
\end{tabular}

\section{Matéria-prima}

As cenouras utilizadas no experimento foram produzidas numa horta na cidade de Petrolina, região semiárida do estado de Pernambuco, sob cultivo tradicional (irrigado). A cultivar empregada foi a "Brasília" com a colheita realizada no mês de setembro de 2008, 92 dias após a semeadura.

Foram cultivadas cenouras com (T1) e sem composto orgânico (T2), constituído de esterco caprino curtido (40\%) e restos vegetais $(60 \%)$, contendo gramíneas, leguminosas e resíduos de folhas, submetido à decomposição por 45 dias e posteriormente, aplicado (incorporado) nos canteiros.

Após a colheita as raízes foram imediatamente transportadas para o Laboratório de Fisiologia Pós-Colheita da Embrapa Semiárido e ao Laboratório de Físico-Química do IFET Sertão Pernambucano.

\section{Métodos - Análises físico-químicas}

As cenouras foram avaliadas através dos seguintes parâmetros na fase de pós-colheita:

Umidade: $\mathrm{O}$ conteúdo de umidade foi determinado com a metodologia da AOAC (1997) para frutos, sendo adaptada para cenoura, onde foi pesado aproximadamente $2 \mathrm{~g}$ de amostra, cortada em finas fatias e colocadas em cadinhos de alumínio, previamente tarados. $\mathrm{O}$ conjunto cadinho e amostra foram colocados em uma estufa à vácuo por um período de $24 \mathrm{~h}$ a $70^{\circ} \mathrm{C}$.

Sólidos solúveis totais (SST): $\mathrm{O}$ teor de sólidos solúveis ( ${ }^{\circ}$ Brix) foi determinado por leitura direta em refratômetro de bancada, com correção de temperatura realizada através de tabela proposta pelo Instituto Adolfo Lutz (1985).

Acidez Total Titulável (ATT): foi determinada por titulometria, segundo normas do Instituto Adolfo Lutz (1985), com resultados expressos em \% de ácido cítrico.

Relação SST/ATT: determinada pelo quociente entre as duas variáveis.

Teor de carotenóides: A extração dos carotenóides totais foi feita de acordo com metodologia da AOAC (1997). A determinação baseia-se na extração do mesmo em hexano e álcool isopropílico, com posterior leitura em espectrofotômetro no comprimento de onda de $450 \mathrm{~nm}$.

Firmeza: foi determinada com auxílio de um penetrômetro de bancada, através de duas medições na seção equatorial em uma mesma raiz, obtendo-se a pressão requerida à penetração em Newton (Coelho, 1994). Também utilizou-se igual procedimento para as repetições que foram armazenadas durante cinco dias para análise da vida pós-colheita das cenouras.

Os dados obtidos foram submetidos à ANOVA, avaliados e comparados entre si, utilizando o software SISVAR 4.2 (2003); o delineamento estatístico utilizado foi inteiramente casualizado com três repetições. 
Acácio Figueiredo Neto et al.

\section{Resultados e discussão}

Os valores das análises físico-químicas da cenoura estão apresentados na Tabela 2. A umidade da cenoura foi maior em raízes obtidas do cultivo com composto orgânico (T1). Isto é um fator importante para a qualidade da cenoura, já que fornece informações sobre a sua tex- tura e, também, aumenta o valor econômico do vegetal por apresentar maior massa.

Quanto ao teor de carotenóides totais as cenouras que receberam a aplicação do composto orgânico no seu cultivo apresentaram maiores valores (Tabela 2), corroborando com os resultados obtidos por Evers (1989), que constataram maiores concentrações de carotenóides em cenouras cultivadas com fertilizantes orgânicos, quando comparadas àquelas cultivadas com fertilizantes minerais.

Tabela 2. Características físico-químicas de cenouras produzidas com (T1) e sem (T2) composto orgânico, Petrolina - PE, 2008.

\begin{tabular}{cc|c|c|c|c}
\hline \multirow{2}{*}{ Tratamentos } & \multicolumn{5}{c}{ Variáveis } \\
\cline { 2 - 6 } & Umidade \% & $\begin{array}{c}\text { Carotenóides } \\
(\mathrm{mg} / 100 \mathrm{~g})\end{array}$ & $\begin{array}{c}\text { Acidez } \% \\
(\mathrm{AC})\end{array}$ & $\begin{array}{c}\text { SST } \\
\left({ }^{\circ} \text { Brix }\right)\end{array}$ & $\begin{array}{c}\text { SST/AC } \\
(\text { ATT })\end{array}$ \\
\hline T1 & $89,8 \mathrm{a}$ & $8,96 \mathrm{a}$ & $0,23 \mathrm{a}$ & $7,2 \mathrm{a}$ & $30,8 \mathrm{a}$ \\
$\mathrm{T} 2$ & $88,3 \mathrm{~b}$ & $6,46 \mathrm{~b}$ & $0,24 \mathrm{a}$ & $6,0 \mathrm{~b}$ & $25,1 \mathrm{~b}$ \\
\hline $\mathrm{CV} \%$ & 0,36 & 2,82 & 3,50 & 2,91 & 3,75 \\
\hline
\end{tabular}

(Médias seguidas de letras iguais nas colunas não diferem entre si pelo teste de Tukey a 5\% de probabilidade).

Verifica-se que a utilização do composto permite que a raiz da cenoura desenvolva uma boa quantidade de carotenóides, ideal para o consumo pós-colheita. Segundo Filgueira (2000), quanto mais intensa for a coloração, mais elevado é o teor de betacaroteno e maior o valor nutricional.

Os resultados obtidos para acidez das cenouras foram expressos em \% de ácido cítrico, não sendo observadas diferenças entre os tratamentos. Provavelmente, isso ocorreu porque os ácidos orgânicos, geralmente, decrescem após o amadurecimento, a colheita e durante a armazenagem devido à oxidação para produção de energia no ciclo de Krebs (Fenema, 1985).

Os valores da concentração de sólidos solúveis totais representam os ácidos, os sais, as vitaminas, os aminoácidos, algumas pectinas e os açúcares presentes nos vegetais. São usados como um índice dos açúcares totais, indicando o grau de maturidade (Bleinroth, 1991). A ce- noura cultivada com composto orgânico apresentou maior ${ }^{\circ}$ Brix. De acordo com Chitarra \& Chitarra (2005) a relação SST/ATT nos vegetais pode ser considerada como um critério de avaliação do "flavor" e um aumento pode significar incremento de sabor, além de ser indicativo do nível de amadurecimento. No caso em estudo, verificou-se que a aplicação do composto orgânico aumentou a relação SST/ATT, devido ao aumento no teor de sólidos solúveis, indicando assim, uma melhoria nos caracteres organolépticos da cenoura.

As medidas físicas encontram-se na Tabela 3. Nota-se que o peso das cenouras cultivadas com o composto orgânico foi maior. Esse resultado é importante, pois demonstra que é possível obter maiores lucros, quando vendidas no peso. Já o comprimento e o diâmetro não foram afetados pela adição de composto orgânico. 
Acácio Figueiredo Neto et al.

Tabela 3. Medidas dos parâmetros físicos de cenouras produzidas com (T1) e sem (T2) composto orgânico ${ }^{1}$.

\begin{tabular}{ccccc}
\hline \multirow{2}{*}{ Tratamentos } & \multicolumn{4}{c}{ Variáveis } \\
\cline { 2 - 5 } & Peso (g) & Comprimento (mm) & Diâmetro (mm) & Firmeza (N) \\
\hline T1 & $116,4 \mathrm{a}$ & $132,7 \mathrm{a}$ & $32,3 \mathrm{a}$ & $97,6 \mathrm{a}$ \\
T2 & $73,5 \mathrm{~b}$ & $136,5 \mathrm{a}$ & $29,9 \mathrm{a}$ & $92,8 \mathrm{~b}$ \\
\hline CV\% & 18,77 & 9,05 & 10,64 & 3,11 \\
\hline
\end{tabular}

(Médias seguidas de letras iguais nas colunas não diferem entre si pelo teste de Tukey a 5\% de probabilidade)

A firmeza dos vegetais diminui com a maturidade, sendo uma característica física que interfere na aceitabilidade das raízes pelo consumidor. Esta característica é obtida através do emprego de medidores de resistência ou textura, onde o penetrômetro é o aparelho mais utilizado. Após a compressão do vegetal obtémse uma medida que equivale à força necessária para vencer a resistência dos tecidos vegetais (Coelho, 1994). Nota-se, que as cenouras produzidas com composto orgânico apresentaram maiores valores de firmeza, possuindo, maior crocância, ou seja, uma melhor textura.

As principais variáveis utilizadas para a determinação da qualidade pós-colheita de cenoura são firmeza da polpa, teor de sólidos solúveis, perda de peso e as aparências externa e interna. Porém, a firmeza da polpa indica a aceitação direta do produto pelo consumidor final, a perda de peso e a própria aparência externa da cenoura fornecem indicações sobre o potencial de vida útil pós-colheita desta hortaliça.

Verificou-se que a firmeza da cenoura "Brasília" durante cinco dias de vida póscolheita permaneceu estável, quando produzida com composto orgânico (Tabela 4), enquanto que aquelas cultivadas sem composto orgânico, apresentaram redução significativa da firmeza a partir do terceiro dia.

Tabela 4. Avaliação de firmeza da cenoura durante cinco dias de vida pós-colheita.

(Médias seguidas de letras iguais, minúsculas nas linhas e maiúsculas nas colunas, não diferem entre si pelo teste de Scott-Knott a 5\% de probabilidade).

\begin{tabular}{cc|c|c|c|c}
\hline \multirow{2}{*}{ Tratamentos } & \multicolumn{5}{c}{ Dias Após a Colheita (Firmeza N) } \\
\cline { 2 - 6 } & 1 & 2 & 3 & 4 & 5 \\
\hline $\mathrm{T} 1$ & $95,8 \mathrm{a}$ & $92,3 \mathrm{a}$ & $89,1 \mathrm{a}$ & $89,0 \mathrm{a}$ & $88,8 \mathrm{a}$ \\
$\mathrm{T} 2$ & $94,9 \mathrm{a}$ & $91,4 \mathrm{a}$ & $88,4 \mathrm{~b}$ & $87,8 \mathrm{~b}$ & $84,0 \mathrm{~b}$ \\
\hline $\mathrm{CV} \%=3,88$ & \multicolumn{5}{c}{} \\
\hline
\end{tabular}

\section{Conclusão}

A aplicação do composto orgânico no cultivo das cenouras da cultivar "Brasília" melhora a qualidade das raízes.

O aumento da concentração de sólidos solúveis totais e o aumento da relação SST/ATT produzidas com composto orgânico indicam uma melhoria das características organolépticas.

Os valores de carotenóides totais foram maiores para cenouras produzidas com composto orgânico, evidenciando uma melhor característica nutricional. 
Acácio Figueiredo Neto et al.

Cenouras produzidas com composto orgânico apresentaram maior firmeza na vida pós-colheita.

\section{Referências}

AOAC. ASSOCIATION OF OFFICIAL ANALYTICAL CHEMISTS. Official Methods of Analysis of AOAC international. 16 ed. Maryland: AOAC, 1997, 1141p.

ARAUJO, C.; ZÁRATE, N.A.H.; VIEIRA, M.C. Produção e perda de massa pós-colheita de cenoura "Brasília", considerando doses de fósforo e de cama de frango semi decomposta. Revista Acta Scientiarum Agronomy, Maringá - PR, v.26, n.2, p.131-138, 2004.

BLEINROTH, E.W. Determinação do ponto de colheita, maturação e conservação das frutas. In: Industrialização de Frutas. Manual Técnico, n.8. Campinas: ITAL, p.1-15, 1991. 206 p.

CHITARRA, M.I.F. \& CHITARRA, A.B. Póscolheita de frutas e hortaliças: fisiologia e manuseio, 2 ed. Lavras - MG, Ed. UFLA, 2005. 785 p.il.

COELHO, A.H.R. Qualidade Pós-Colheita de Pêssegos. Informe Agropecuário, v.17, n.180, p.31-39, 1994.

EMBRAPA, Empresa Brasileira de Pesquisa Agropecuária. Cultivo da cenoura (Daucus carota L.), Instrução técnica. Centro Nacional de Pesquisa de Hortaliças, Brasília - DF, 2007.

EVERS, A.M. The role of fertilization practices in the yield and quality of carrot (Daucus carota L.). Journal of Agricultura Science in Finland, Helsinki, 61, p.329, 1989.

FENEMA, Q. R. Food Chemistry. Marcel Dekker, New York, 991p. 1985.

FILGUEIRA, F.A.R. Novo Manual de Olericultura. $1^{\text {a }}$ ed. Viçosa - MG, Editora UFV, 2000. 402p.

FILGUEIRA, F.A.R. Novo Manual de Olericultura: Agrotecnologia Moderna na Produ- ção e Comercialização de Hortaliças. $2^{\mathrm{a}} \mathrm{ed}$. Viçosa - MG, Editora UFV, 2003. 413p.

INSTITUTO ADOLFO LUTZ. Normas analíticas do Instituto Adolfo Lutz: métodos químicos e físicos para análises de alimentos. 3 edição, São Paulo: O Instituto, 1985, v.1, 533p.

KIEHL, E.J. Fertilizantes orgânicos. Piracicaba - SP: Agronômica Ceres, 1985.

MULLER, J.J.V. Aspectos do armazenamento de cenouras (Daucus carota L.). In: Muller, J.J.V.; CASALI, V.W.D. Seminários de Olericultura. Viçosa - MG: Imprensa Universitária, v.5, p.01-25, 1982.

NEGRINI, A.C.A., MELO, P.C.T. Efeito de diferentes compostos e dosagens na produção de cenoura (Daucus carota L.) em cultivo orgânico. Revista Brasileira de Agroecologia, v.2, n1., p. 1036-1039, fev. 2007.

NOGUEIRA, F.D. Solo, nutrição e adubação da cenoura e mandioquinha-salsa. Informe Agropecuário, Belo Horizonte - MG, v.10, n.120, p.28-32, 1984.

SALGADO, J.A.A., ALMEIDA, D.L., GUERRA, J.G.M., RIBEIRO, R.L.D., SUDO, A. Balanço de nutrientes em cultivos de hortaliças sob manejo orgânico. Soropédica: Embrapa Agrobiologia, 9p. 1998.

SISVAR 4.2 (Build 39) - Software estatístico. DEU/UFLA. Lavras - MG. Copyrith Daniel Furtado Ferreira 1999-2003.

SPAGNOL, W.A.; PARK, K.J.; MONTEIRO, J.M. Taxa de respiração de cenouras minimamente processadas e armazenadas em diferentes temperaturas. Ciência e Tecnologia Alimentos, Campinas, v.26, n.3, p. 552-554, set. 2006.

SOUZA, P.A.; NEGREIROS, M.Z.; MENEZES, J.B.; BEZERRA NETO, F.; SOUZA, G.L.F.M; CARNEIRO, C.R.; QUEIROGA, R.C.F. Características químicas de folhas de alface cultivada sob efeito residual da adubação com composto orgânico. Horticultura Brasileira, Brasília, v.23, n.3, p.699-702, set. 2005.

VIDIGAL, S.M.; RIBEIRO, A.C.; CASALI, V.W.D.; FONTES, L.E.F. Resposta da alface 
Acácio Figueiredo Neto et al.

(Lactuca sativa L.) ao efeito residual da adubação orgânica I - ensaio de campo (a). Revista Ceres, Viçosa - MG, v.42, n.239, p.8088, 1995.

VIEIRA, M.C. Crescimento e produção de cenoura, considerando cama de aviário semi decomposta, incorporada e em cobertura, em Dourados-MS. SOB Informa, Rio de Janeiro, v.15, n.1, p.17-19, 1996. 